Tasova, M. and M. Özkurt, Korunga (Onobrychis sativa L.) Tohumluğunun Bazı Biyoteknik ve Renk Özelliklerinin Belirlenmesi. International Journal of Life Sciences and Biotechnology, 2018. 1(2): p. 4858.

\title{
Korunga (Onobrychis sativa L.) Tohumluğunun Bazı Biyoteknik ve Renk Özelliklerinin Belirlenmesi
}

\author{
Muhammed Tasova ${ }^{1 *}$, Mahir Özkurt ${ }^{1}$
}

Özet: Baklagil yem bitkilerine ait hasat ve hasat sonrası işlemlerinde kullanılan makine ve ekipman tasarımlarında, bu bitkilerin tohumlarına ait bazı özelliklerin bilinmesi gereklidir. Bu çalışmada, Özerbey korunga çeşidi tohumunun bazı biyoteknik özellikleri ile renk değerleri belirlenmiştir. Tohumun temel boyut özelliklerine ait ortalama uzunluk, genişlik ve kalınlık değerlerinin sırasıyla 6.14, 4.57 ve 3.09 mm olduğu tespit edilmiştir. Bununla beraber, hesaplanan geometrik ortalama çap değeri $4.41 \mathrm{~mm}$, küresellik \% 72.07 ve yüzey alanı değeri ise; $61.34 \mathrm{~mm}^{2}$ olarak bulunmuştur. Tohumun hacimsel özellikler incelendiğin de ise bin dane ağırlığının $22 \mathrm{~g}$, tohum hacminin $0.59 \mathrm{~cm}^{3}$, gerçek hacim ağırlığının 592.11 $\mathrm{kg} / \mathrm{m}^{3}$, yığgın hacim ağırlığının $300 \mathrm{~kg} / \mathrm{m}^{3}$ ve porozite değerinin ise $\% 39.33$ olduğu belirlenmiştir. Tohumun ölçülerek belirlenen renk özelliklerinden ortalama parlaklık (L) değerinin 42.81, kırmızı-yeşil (a) değerinin 6.54, sarı-mavi (b) değerinin 12.49 olduğu tespit edilmiştir. Bu değerler kullanılarak hesaplanan ortalama kroma (C) ve hue ${ }^{\circ}$ değerleri ise sırasıyla 14.12 ve 62.22 olarak bulunmuştur.

Anahtar Kelimeler: Korunga tohumu, fiziksel ve renk değerleri

\section{Determination of Some Biotechnic and Color Properties of Sainfoin (Onobrychis sativa L.) Seed}

\begin{abstract}
In the design of machinery and equipment used in harvesting and post-harvest operations of legume forage plants, some properties of seeds of these plants should be known. In this study, some biotechnical properties and color values of Özerbey sainfoin seed were determined. The average length, width and thickness values of the seed size were determined as $6.14,4.57$ and $3.09 \mathrm{~mm}$ respectively. However, the calculated geometric mean diameter value is $4.41 \mathrm{~mm}$, the sphericity $72.07 \%$ and the surface area value; $61.34 \mathrm{~mm}^{2}$. When the volumetric properties of the seed were examined, it was determined that the weight of the grain was $22 \mathrm{~g}$, the seed volume was $0.59 \mathrm{~cm}^{3}$, the actual volume weight was 592.11 $\mathrm{kg} / \mathrm{m}^{3}$, the bulk volume was $300 \mathrm{~kg} / \mathrm{m}^{3}$ and the porosity value was $39.33 \%$. It was determined that the average brightness (L) value of the color determined by measuring the seed was 42.81, red-green (a) value was 6.54 and yellow-blue (b) was 12.49 . The mean chroma (C) and hue ${ }^{\circ}$ values calculated using these values were found as 14.12 and 62.22 , respectively.b) 12.49 and the chroma (C) and hue ${ }^{\circ}$ values calculated $^{\circ}$ using these values, respectively 14.12 and 62.22 .
\end{abstract}

Key words: Sainfoin seed, physical and color value

\footnotetext{
${ }^{1}$ Tokat Gaziosmanpasa Üniversitesi, Ziraat Fakültesi, Biyosistem Mühendisliği Bölümü,

*Sorumlu yazar: muhammed.tasova@gop.edu.tr
} 


\section{Giriş}

Korunga (Onobrychis sativa L.), fabaceae familyasından olan bir baklagil yem bitkisi olup, genellikle pembe renkli ve salkım çiçek yapısına sahiptir. Korunga bitkisinin bir salkımında ortalama 5-80 adet çiçek bulunup, yaprak ekseninde ise ortalama 5-14 çift yaprakçığı olan bir yem bitkisidir. Sulu tarımın yapılamadığı ve verimsiz arazi koşullarında adaptasyon yeteneği yüksek olan korunga, her iklimde yetişebilen kuraklığga ve özellikle soğuğa oldukça dayanıklı çok yıllık bir bitkidir [1]. Yetiştiriciliğinin yapıldığı ilk yıl fide döneminde soğuğa karşı hassas bir bitki olup, ikinci yıldan sonra ise genellikle soğuktan zarar görmemektedir. Soğuğa karşı, yaşlandıkça dayanıklılığı artmakta ve sıcaklık istekleri ise yonca bitkisinden daha azdır. Doğu, Güney Doğu ve İç Anadolu Bölgelerindeki iklim koşullarındaki ekim sistemine çok uygun bir bitki olup, yetiştiği koşullarda verimli bir şekilde yetişebilecek başka bir baklagil yem bitkisinin olmadığ bilinmektedir $[2,3]$.

Korunga bitkisi, Dünya'da Kafkasya, Suriye, İran ve Türkiye' de yaygın bir şekilde yetişmekle birlikte ülkemizde ise Erzincan, Erzurum, Van, Çorum ve Kayseri gibi karasal iklimin görüldüğü birçok yerde verimli bir şekilde yetişmektedir [4]. Bununla beraber tane içeriğindeki etken maddelerden (kalsiyum, fosfor, ve protein) dolayı hayvanların sindirim organlarında bazı gazların vücuttan atılmasına yardımcı olması özelliğiyle hayvanların beslenmesi üzerinde önemli bir bitkidir $[5,6,7]$.

Türkiye İstatistik Kurumu 2017 yılı verilerine göre, ülkemizdeki mevcut tarım arazisinin ortalama 24 milyon hektar olduğu ve bu miktarın ortalama \% 66 oranında tahıl [8] ve ortalama \% 9.84' lük kısmında ise yem bitkisi yetiştirildiği bilinmektedir [9]. 
Birçok bitkinin hasat ve hasat sonrasında (temizleme, sınıflandırma ve depolama) yapılan işlemlerinde uygun ekipman ve işletme özelliğinin seçimi hasat ve depolama verimini önemli oranda etkilemektedir. Bu özelliklerin başında ise, ürünle ilgili biyoteknik özellikler gelmektedir. Bu özelliklerden bazıları tohuma ait geometrik, hacimsel, sürtünme ve renk özellikleridir. Bu parametre değerlerinin bilinmesi, ürünün hasat ve hasat sonrasında oluşan kayıp miktarlarının azaltılmasında önem arz etmektedir. Yetiştirilen yem bitkileri içerisinde büyük bir paya sahip olan korunga bitkisinin hasat ve sonrasında yapılan işlemlerinde de kullanılan alet ve ekipmanlara ait işletme parametrelerinin de bilinmesi gereklidir.

Literatürde; Lavandin [10], chia [11], adaçay1 [12], biber [13], kanola [14] ve çeltik [15] gibi birçok bitki tohumlarına ait hasat parametreleri açısından önemli olan tohumların bazı fiziksel özellerinin belirlenmesi konusunda çalışmalar yapılmıştır. Bu çalışmada; Özerbey çeşidi korunga tohumlarına ait bazı fizik özellikler ve renk değerlerinin belirlenmesi amaçlanmıştır.

\section{Materyal Yöntem}

\section{Kullanılan materyal}

Araştırmada 2003 yılında Tarla Bitkileri Merkez Araştırma Enstitüsü tarafından tescil edilen Özerbey korunga çeşidi kullanılmış ve söz konusu deneme materyali Tarım İşletmeleri Genel Müdürlüğüne bağlı Ulaş Tarım İşletmesinden elde edilmiştir. Çalışma sonuna kadar tohumlar $+4^{\circ} \mathrm{C}$ sıcaklıktaki buzdolabında muhafaza edilmiştir. Ekşi (2015), tohumların 0-5 ${ }^{\circ} \mathrm{C}$ sıcaklıkları arasında saklanabileceğini ifade etmiştir [16].

\section{Temel boyut özelliklerinin belirlenmesi}


Özerbey çeşidinin temel boyut özellikleri olan; uzunluk, genişlik ve kalınlık değerlerini belirlemek için rastgele seçilen 100 adet tohum, 0.01 hassasiyetli kumpasla ölçülmüştür [14]. Kullanılan dijital kumpas, Loyka marka KMP100 modeldir.

\section{Geometrik ortalama çap (Dg) ve küresellik $(\Phi)$ değerlerinin belirlenmesi}

Tohumun geometrik ortalama çap (G.O.Ç) ve küresellik değerlerini belirlemek için 3 ve 4 nolu eşitlikler kullanılmıştır [17, 18].

$D g=(L W T) 1 / 3$

$\Phi=((L W T) 1 / 3 / L) \times 100$

Eşitliklerde kullanılan Dg: Geometrik ortalama çap değeri $(\mathrm{mm}), \Phi$ : küresellik değeri

(\%), L: materyalin uzunluk değeri $(\mathrm{mm}), \mathrm{W}$ : materyalin genişlik değeri $(\mathrm{mm})$ ve $\mathrm{T}$ : materyalin kalınlık değerleridir (mm)' dir.

\section{Yüzey alanının belirlenmesi}

Materyalin yüzey alanı (S) 5 nolu eşitlik kullanılarak belirlenmiştir [17].

$S=\pi \cdot D g 2$

Eşitlikteki S: yüzey alanı $\left(\mathrm{mm}^{2}\right)$ değeridir.

\section{Yığın ve gerçek hacim ağırlığının belirlenmesi}

Korunga tohumunun ortalama 1000 dane ağırlık değerlerinin belirlenmesi için; 0.01 hassasiyetli hassas terazi ile ağırlıkları ölçülerek hesaplanmıştır. Materyalin yığın hacim ağırlığının belirlenmesi için beher kullanılmıştır. Tane hacmi (TH) ve tane hacim ağırlığı (THA) değerlerinin belirlenmesi için ise; saf suyun yer değiştirme metodundan 
yararlanılmıştır. Ürünün gerçek hacim ağırlığı (HA) değeri ise; 6 nolu eşitlikle belirlenmiştir [19]. Kullanılan hassas terazi Sartouris marka cihazdır.

$H A=[m b / V b]$

Eşitlikte kullanılan mb: meyvenin ağırlığı $(\mathrm{kg}), \mathrm{Vb}$ : meyvenin hacmi $\left(\mathrm{m}^{3}\right)$.

\section{Porozite değerlerinin belirlenmesi}

Tohumunun ortalama porozite değerleri, tane hacim ağırlığı ile gerçek hacim ağırlık farkının hacim ağırlığına oranlanmasıyla hesaplanmıştır. Porozite değerlerini belirlemek için aşağıdaki 7 nolu eşitlikle hesaplanmıştır.

$P=[(T H A-H A) / H A] \times 100$

Eşitlikteki, THA: meyvenin tane hacim ağırlığ $\mathrm{kg} / \mathrm{m}^{3}$, HA: meyvenin hacim ağırlığ $\mathrm{kg} / \mathrm{m}^{3}$ değerleridir.

\section{Ölçülen renk değerlerinin belirlenmesi}

Korunga tohumunun renk değeri ölçümleri için; Minolta marka CR300 model renk ölçer kullanılmıştır. Renk ölçer ile tohumun Hunter Lab Chromameter renk değerleri olan L, a ve b değerleri ölçülmüştür.

$\mathrm{Bu}$ değerler;

Korunga tohumuna ait ölçülen L değeri; Materyalin parlaklık değerini ifade ederken 0100 arasında değerler almaktadır. L değeri, 0 olduğunda korunga tohumuna ait rengin 
siyah, yani yansımanın olmadığını ifade ederken, L değeri 100 olduğunda ise tohum renginin beyaz, yani yansımanın tam olduğunu ifade etmektedir. Korunga tohumuna ait ölçülen diğer renk değerlerinden olan a; kırmızı-yeşil, b; sarı-mavi renkleri ifade ederken sırasıyla;,+- işaretlerini almaktadır. Tohumda ölçülen, renk değerleri $a=0$ ve $b=0$ olduğu durumda ise ürün renginin gri olduğunu göstermektedir [20].

Ölçülen L, a ve b değerleri ticari açıdan tek başlarına bir anlam ifade etmezken bu değerler kullanılarak hesaplanan kroma ve hue açısı değerleri ürünlerin renk değerleri hakkında daha doğru bilgiler vermektedir.

\section{Hesaplanan renk değerlerinin belirlenmesi}

Kroma: Ürün renginin tonunu ifade ederken solgun renklerde düşük, canlı renklerde ise yüksek değerler almaktadır. [21], kroma değeri 8 nolu eşitlik kullanarak hesaplandığını ifade etmişlerdir.

$C=\left(a^{2}+b^{2}\right)^{1 / 2}$

Hue: Renk açısı değerinin $360^{\circ}$ lik bir renk gradyantında her açıya karşı1lı gelen renklerin görülmesini kolaylaştırır (Şekil 1).

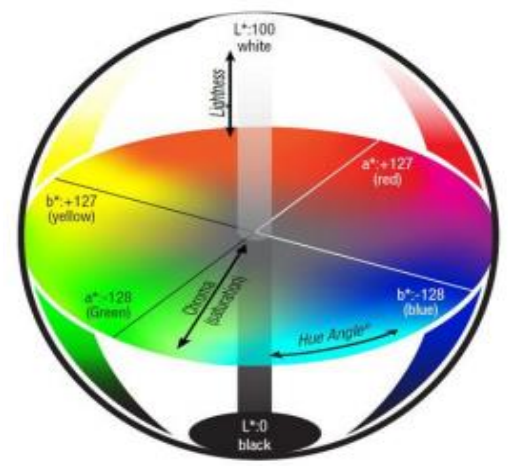

Şekil 1. Hue açısının renk radyantı [22, 23] 
Şekil 1' göre, $0^{\circ} \mathrm{kırmız1,} 90^{\circ}$ sarı, $180^{\circ}$ yeşil ve $270^{\circ}$ ise ürünün mavi renkte olduğunu ve bu açı değerlerinin aralarına denk gelen kısımlarda ara renklerin oluştuğu görülmektedir.

[24], hue renk açısı değerinin 9 nolu eşitlik kullanılarak hesaplandığını ifade etmişlerdir.

$\mathrm{h}^{\circ}=\tan ^{-1}\left(\frac{\mathrm{b}}{\mathrm{a}}\right)$

Tohumun ölçülen ve hesaplanan renk değerlerinin "maksimum ve minimum" değerleri belirlenmiştir.

\section{Araştırma Bulguları ve Tartışma}

Korunga tohumuna ait belirlene bazı biyoteknik özellikleri Tablo 1' de verilmiştir.

Tablo 1. Özerbey korunga çeşidi tohumunun biyoteknik özellikleri

\begin{tabular}{lcccc}
\hline Fiziksel özellikler & Birim & Minimum & Maksimum & Ortalama \\
\hline Geometrik özellikleri & & & & \\
\hline Uzunluk, (L) & $\mathrm{mm}$ & 5.15 & 7.55 & 6.14 \\
Genişlik, (W) & $\mathrm{mm}$ & 3.87 & 5.89 & 4.57 \\
Kalınlık, (T) & $\mathrm{mm}$ & 2.20 & 4.03 & 3.09 \\
Geometrik & $\mathrm{mm}$ & 3.73 & 5.21 & 4.41 \\
Ortalama çap (G.O.Ç) & $\%$ & 62.93 & 84.65 & 72.07 \\
Küresellik, (K) & $\mathrm{mm}$ & 43.66 & 85.29 & 61.34 \\
Yüzey alanı, (S) & & & & \\
\hline Hacimsel özellikler & $\mathrm{g}$ & 0.10 & 0.13 & 0.11 \\
\hline Tane ağırlı̆̆1 & $\mathrm{kg} / \mathrm{m}^{3}$ & 450.00 & 680.23 & 521.31 \\
Y. Hacim ağırlığı & $\mathrm{kg} / \mathrm{m}^{3}$ & 500.00 & 722.22 & 592.11 \\
Tane hacim ağırlığ & $\%$ & 31.77 & 39.33 & 49.33 \\
Porozite & 0.16 & 0.22 & 0.19 \\
Tohum hacmi & $\mathrm{cm}^{3}$ & & &
\end{tabular}

Tablo 1' e göre, tohumuna ait belirlenen ortalama genişlik, kalınlık ve uzunluk değerleri arasında büyük bir fark olduğu görülmektedir. Bulgulara göre, korunga tohumunun küresellik değerine göre ve şekilsel olarak incelendiğinde küreye çok yakın olmadığı 
anlaşılmaktadır. Bunun yanında tohumun tane ağırlığı ise oldukça düşük olduğu belirlenmiştir.

Yapılan çalışmaya göre, uygulamalı chia tohumuna ait kalınlık değerinin, 0.054-0.060 mm arasında değiştiğini ifade etmişlerdir [11]. Çalışmada, kırmızı mercimeğin bin tane ağırlığgının 56.30-64.10, porozite değerinin \% 40.60-43.05 ve kalınlık değerinin ise, 2.34 $2.54 \mathrm{~mm}$ arasında değiştiğini belirlemişlerdir [25]. Reyhan tohumuna ait ortalama uzunluk, genişlik ve kalınlık değerlerini sırasıyla 3.22, 1.84 ve 1.36 olarak belirlemişlerdir. Bununla beraber çalışmalarında, ortalama yığın ağırlığını, 320.24 kg/m ve ortalama tohum hacmini ise $7.55 \mathrm{~mm}^{3}$ olarak belirlemişlerdir [26]. Başka bir çalışmada ise bazı çeltik çeşitlerinin hacim değerlerinin 26.21-34.74 $\mathrm{mm}^{3}$ aralığında değiştiğini belirlemişlerdir. $\mathrm{Bu}$ değerlerin, Özerbey çeşidi korunga tohumuna ait hacim değerlerinden oldukça düşük olduğu tespit edilmiştir [27]. Özerbey çeşidi korunga tohumuna ait ölçülen ve hesaplanan bazı renk özelliklerine ait ortalama, maksimum, minimum değerleri Tablo 2' de verilmiştir.

Tablo 2. Özerbey korunga çeşidi tohumunun bazı renk değerleri

\begin{tabular}{lccc}
\hline Renk özellikleri & Minimum & Maksimum & Ortalama \\
\hline Ölçülen & & & \\
\hline Parlaklık, L & +40.20 & +48.29 & +42.81 \\
Kırmızı-Yeşil, a & +5.65 & +7.51 & +6.54 \\
Sar1-Mavi, b & +11.53 & +17.74 & +12.49 \\
\hline Hesaplanan & & & \\
\hline Kroma, C & +13.06 & +18.85 & +14.12 \\
Hue $^{\circ}, \mathrm{H}$ & +58.14 & +70.22 & +62.22 \\
\hline
\end{tabular}

Tablo 2' ye göre tohuma ait en yüksek parlaklık (L) değerinin; 48.29, en düşük parlaklık değerinin ise, 40.20 olarak belirlenmiştir. Kırmızı (a) ve sarılık (b) değerlerinde ise en büyük ve en küçük olmak üzere sırasıyla; 7.51-5.65 ve 17.74-11.53 olarak belirlenmiştir. 
Korunga tohumuna ait hesaplanan hue ${ }^{\circ}$ renk değeri Şekil 1' deki renk karşıllı̆ına göre incelendiğinde; turuncu ile sarı renk arasında yer aldığı görülmektedir. Yapılan çalışmada, baklanın bazı fiziksel özelliklerinin belirlenmesi konulu çalışmalarında, ölçtükleri L, a ve b değerlerinin sırasıyla 40.63, -11.53 ve 19.70 olarak belirlerken, hesapladıkları kroma ve hue ${ }^{\circ}$ renk değerlerinin ise sirasıyla 22.83 ve 120.35 olarak bulmuşlardır. Aynı çalışmadaki bulgulara göre, baklanın parlaklık değeri ile korunga tohumunun parlaklık değerlerinin birbirlerine yakın olduğu görülmüştür [28].

\section{Sonuç}

Ülkemizdeki yem bitkileri, üretim miktarı açısından incelendiğinde korunga bitkisi önemli bir paya sahiptir. Bununla beraber Özerbey korunga çeşidinin hasat ve hasat sonrasında kullanılan makine, alet ve ekipmanların hassas bir şekilde tasarlanması için ürünün tohumuna ait bazı biyoteknik özellikleri ile renk değerlerinin bilinmesi, bu işlemler esnasında gerçekleşebilecek hasat kayıplarını azaltma ve depolama süresini iyileştirilmesine katk1 sağlayacağı düşünülmektedir.

Çalışma kapsamında; Özerbey korunga çeşidi tohumunun geometrik, hacim ve renk değerleri belirlenerek literatürde yer alan benzer tohumların özellikleriyle kıyaslanmış ve bazı parametrelerde benzer değerlerin olduğu görülmüştür.

\section{Kaynaklar}

1. Avcıŏlu, R., Hatipoğlu, R. ve Karadağ, Y., Yem bitkileri. Buğdaygil Yem bitkileri ve Diğer Familyalardan Yem bitkileri. Tarım ve Köyişleri Bakanlığı, Tarımsal Üretim ve Geliştirme Genel Müdürlüğü. 2009. 843, İzmir.

2. Elçi, Ş., H. Ekiz ve Sancak, C., Problems of trefoil (Onobrychis sativa) production in Turkey. Turkey 3rd Rangeland and Forage Crops Congress. 1996. 17-19 July, Erzurum.

3. Okcu, M. ve Şengül, S., A Study On The Determınatıon of The Morphologıcal, Yield and Qualıty Characteristics of Some Sainfoin Species (Onobrychis Spp.) Natıve To East Anatolia. Pakistan Journal of Botany. 2014. 46(5): 1837-1842. 4. 
4. Eminağaoğlu, Ö. ve Aksu, G., Türkiye' nin Doğal-Egzotik Ağaç ve Çalıları 1. 2014. (Erişim Tarihi: 23.10.2018).

5. Rumball, W. ve Claydon, B., Germplasm release 'G35' Sainfoin (Onobrychis vicifolia). Journal of Agricultural Research, 2005. 48: 127-128.

6. Häring, D.A., Suter, D., Amrhei,n N. ve Lüscher, A., Biomass allocation is an important determinant of the tannin concentration in growing plants. Annals of Botany. 2007. 99, 111-120.

7. Koç, A. ve Akdeniz, H., Gözlü ve Altınova Tarım İșletmelerinde Islah Edilen Korunga Çeşitlerinin Verim ve Bazı Tarımsal Özellikleri Üzerine Ön Araştırmalar. Kahramanmaraş Doğa Bilimleri Dergisi. 2017. 20 (Özel Sayı), 6-12.

8. Diler, A., Koçyiğit, R., Yanar, M., Aydın, R., Güler, Olcay ve Avcı, M., Erzurum ili Hınıs ilçesi sığırcılık işletmelerinde sığır besleme uygulamaları üzerine bir araştırma. Anadolu Tarım Bilimleri Dergisi. 2016. 31, 149-156.

9. $\quad$ TÜIK., https://www.tuik.gov.tr. 2017. (Erişim Tarihi: 24.10.2018).

10. Yılmaz, D. ve Gökduman, M.E., Effect of Moisture Contents on Physical-Mechanical Properties of Lavandin (Lavandula X Intermedia Emeric Ex Loisel.). Journal of Essential Oil Bearing Plants. 2014. 17(6), 1224-123.

11. Dick, M., Costa, T.M.H., Gomaa, A., Subirade, M., Rios, A.O. ve Flores, S.H., Edible film production from chia seed mucilage: Effect of glycerolconcentration on its physicochemical and mechanical properties. Carbohydrate Polymers. 2015. 130: 198-205.

12. Yılmaz, D. ve Gökduman, M.E., Adaçayı (Salvia Officinalis) Bitkisinin Farklı Nem Düzeylerinde Fiziko-Mekanik Özelliklerinin Belirlenmesi. Süleyman Demirel Üniversitesi Ziraat Fakültesi Dergisi. 2015. 10(1): 73-82.

13. Alibaş, I. ve Köksal, N., Determination of physical, mechanical, and structural seed properties of pepper cultivars. International Agrophysics. 2015. 29: 107-113.

14. Özlü, R.R. ve Güner, M., Farklı Nem Düzeylerinde Kanola Tohumlarının Fiziksel Özelliklerinin Belirlenmesi. Gaziosmanpaşa Üniversitesi Ziraat Fakültesi Dergisi. 2016. 33 (Ek Sayı), 10-24.

15. Erdoğan, H. Ve Işık, E., The Effect of Batch Drying at Different Temperatures on Seed Germination, Physical, and Seedling Properties of Paddy (Oryza sativa L.)**. Uludağ Üniversitesi Ziraat Fakültesi Dergisi. 2017. 31(1): 137-147.

16. Ekşi, C., 2015. Tohum Muhafazası. Gıda Tarım ve Hayvancılık Bakalnlığı, Tarımsal Araştırmalar ve Politikalar Genel Müdürlüğü Alata Bahçe Kültürleri Araştırma Enstitüsü Erdemli-Mersin.

17. Mohsenin, N.N., Physical properties of plant and animal materials. Gordon and Breach Science Publishers. 1970. New York.

18. Tabatabaeefar, A., Moisture-dependent physical properties of wheat. International Agrophysics. 2003. 17: 207-211.

19. Deshpande, S.D., Bal, S. and Ojha, T.P., Physical properties of soybean grains. Journal of Agricultural Engineering Research. 1993. 56: 89-92.

20. McGuire, R.G., Reporting of objective color measurements. Hort Science. 1992. 27, 1254-1255.

21. Lopez, J., Vega Galvez, A., Torres, M.J., Lemus Mondaca, R., Quispe Fuentes, I. ve Di Scala, K., Effect of dehydration temperature on physico-chemical properties and antioxidant capacity of goldenberry (Physalis peruviana L.). Chılean Journal Of Agricultural Research. 2013. 73(3), 293300.

22. Agudo, J.E., Pardo, P.J., Sánchez H., Pérez, A. L. ve Suero, M. I., A Low Cost Real Color Picker Based on Arduino Sensors. 2014. 14 (7):11943-11956.

23. Sarıkulak, N., Kirazın farklı kurutucularda kurutulması ve kalite parametrelerinin belirlenmesi. Yıldız Teknik Üniversitesi, Fen Bilimleri Enstitüsü, Kimya Mühendisliği Anabilim Dalı, Yüksek Lisans Tezi. 2017. İstanbul.

24. Polatc1, H. ve Taşova, M., The Effect on Drying Characteristics and Colour Values of Hawthorn Fruit of Temperature Controlled Microwave Drying Method. Türk Tarım - Gida Bilim ve Teknoloji Dergisi. 2017. 5(10): 1130-1135. 
25. Bagherpour, H., Minaei, S. ve Khoshtaghaza, M.H., Selected physico-mechanical properties of lentil seed. International Agrophysics. 2010. 24: 81-84.

26. Razavi, S.M.A., Bostan, A. ve Rezare, M., Image Processing And Physico-Mechanıcal Properties of Basil Seed (Ocımum Basılıcum). Journal of Food Process Engineering. 2008. 33: 51-64.

27. Swaminathan, I. Ve Guha, M., Physical and Engineering Properties of Some Indian Paddy Cultivars and Their Interrelations. International Journal of Engineering Research and ScienceTechnology. 2016. Vol: 5, No:3.

28. Alibaş, İ. ve Okursoy, R., Baklanın (Vicia faba L.) Bazı Teknik Özelliklerinin Belirlenmesi. 27. Tarımsal Mekanizasyon Ulusal Kongresi. 2012. 5-7 Eylül 2012, Samsun. 